\title{
Degradación Heliofotocatalítica de Escherichia coli en Sistemas tipo Desinfección SODIS, con Dióxido de Titanio Modificado
}

\author{
Camilo A. Castro ${ }^{1}$, Alba L. Arámbula ${ }^{2}$, Aristóbulo Centeno ${ }^{1}$, Sonia A. Giraldo ${ }^{1}$ \\ Universidad Industrial de Santander, (1) Escuela de Ingeniería Química, Centro de Investigaciones \\ en Catálisis (CICAT), (2) Escuela de Bacteriología y Laboratorio Clínico, Cra. 27, calle 9, \\ Bucaramanga-Colombia (e-mail: sgiraldo@uis.edu.co)
}

\begin{abstract}
Resumen
Se presenta un estudio sobre la desinfección heliofotocatalítica de agua (DHFCA) en sistemas tipo desinfección solar (Solar Disinfection, SODIS). Se usaron fotocatalizadores basados en dióxido de titanio $\left(\mathrm{TiO}_{2}\right)$ comercial y $\mathrm{TiO}_{2}$ obtenido por el método sol-gel modificados con metales de transición $(\mathrm{Ag}, \mathrm{Fe}, \mathrm{Mo}$ o $\mathrm{Pd})$. Los resultados muestran que la unión de la técnica SODIS con la fotocatálisis permite disminuir el tiempo de exposición a la radiación solar de unidosis de agua infectada comparado con el necesario para la desinfección total cuando se utiliza el sistema SODIS solo. Además, se encontró que la eficiencia de los fotocatalizadores evaluados en la DHFCA depende del método de preparación y de la naturaleza del metal incorporado. La incorporación de $\mathrm{Ag}$ o $\mathrm{Pd}$ aumenta la acción bactericida de la DHFCA. La plata presenta una acción adicional a la fotocatalítica debido a sus propiedades bacteriostáticas, mientras que el Pd mejora la fotoactividad gracias a sus propiedades electrónicas.
\end{abstract}

\section{Escherichia coli Heliophotocatalytic Degradation in Solar Disinfection Systems SODIS, using Modified Titanium Dioxide}

\begin{abstract}
A study concerning the Heliophotocatalytic Disinfection of Water (HPDW), in Solar Disinfection type systems (SODIS) is presented. Photocatalysts based on a commercial titanium dioxide $\left(\mathrm{TiO}_{2}\right)$ and $\mathrm{TiO}_{2}$ obtained by the sol-gel method both modified with transition metals ( $\mathrm{Ag}, \mathrm{Fe}$, Mo or Pd), were used. Results show that the combination of the SODIS technique with photocatalysis reduces the solar irradiation time exposure of a unidosis of infected water, when compared to the one needed using the SODIS technique alone. In addition, it was observed that both, the synthesis method and the nature of the metal modifying the $\mathrm{TiO}_{2}$ influence the efficiency of the photocatalyst evaluated in HPDW. Inclusion of Ag or Pd enhances the bactericide action of the HPDW system. Ag presents an additional effect besides the photocatalytic one due to its bacteriostatic properties, while $\mathrm{Pd}$ enhances the photoactivity due to its electronic properties.
\end{abstract}

Keywords: solar disinfection, titanium dioxide, Escherichia coli, photocatalysts 


\section{INTRODUCCIÓN}

La desinfección solar de agua contenida en botellas de polietilentereftalato (PET) por el método SODIS (Solar Disinfection) es una solución económica y viable para el aprovisionamiento de agua potable en regiones sin redes de distribución de este recurso (Freeman y Szymanski, 2005), pero requiere tiempos prolongados de exposición a la radiación solar para alcanzar la desinfección total (Solarte et al., 1997), lo cual no es posible en algunas regiones donde la intensidad de la radiación no es constante. Utilizar en conjunto la técnica SODIS con la fotocatálisis es una alternativa interesante que permitiría, en principio, disminuir los tiempos de exposición. Con la fotocatálisis se aprovecharía la acción oxidante de los radicales hidroxilo $\left({ }^{\circ} \mathrm{OH}\right)$ producidos durante la irradiación de los fotocatalizadores (Sun et al., 2003). Este radical es una especie transitoria que no genera subproductos cancerígenos a diferencia del proceso de cloración en donde se forman los conocidos DBPs (Disinfection by products) por reacción del cloro con la materia orgánica circundante (Nikolau et al., 2004). El dióxido de titanio $\left(\mathrm{TiO}_{2}\right)$, es un buen candidato ya que se ha utilizado como fotocatalizador en la oxidación de compuestos orgánicos variados (Carp et al., 2004; Hermman, 2005; Marin et al., 2008) y en la degradación de bacterias (Rajagopal et al., 2006; Rengifo-Herrera et al., 2008) y de virus (Zan et al., 2006) con resultados positivos. Sin embargo, su eficiencia como fotocatalizador se afecta por el fenómeno de recombinación de las parejas electrón-hueco $\left(\mathrm{e}^{-}-\mathrm{h}^{+}\right)$ fotogeneradas por absorción de radiación ultravioleta, responsables de la formación de los ${ }^{\circ} \mathrm{OH}$. Modificar el $\mathrm{TiO}_{2}$, incorporándole metales de transición, es una posibilidad que permitiría contrarrestar este fenómeno, ya que estos metales pueden atrapar las especies activas fotogeneradas evitando la rápida recombinación. Se debe tener en cuenta además, que el comportamiento de los fotocatalizadores depende del método de síntesis (Xu et al., 2004), de la cantidad de radiación ultravioleta disponible (Rincón y Pulgarín, 2003), de la naturaleza del metal dopante (Xu et al., 2004) y de su concentración en la matriz del $\mathrm{TiO}_{2}$ (Piera et al., 2003; Yuan et al., 2006; Ni et al., 2007).

En este trabajo se presenta un estudio sobre la DHFCA de unidosis de agua (en botellas de PET) con una población bacteriana de Escherichia coli, combinando el sistema SODIS con fotocatalizadores de $\mathrm{TiO}_{2}$ modificado con metales de transición.

\section{MATERIALES Y MÉTODOS}

\section{Síntesis de los fotocatalizadores}

Se prepararon dos series de fotocatalizadores basados en $\mathrm{TiO}_{2}$. La primera serie se preparó mediante el método de impregnación húmeda del $\mathrm{TiO}_{2}$ (Degussa $\mathrm{P}-25,80 \%$ de anatasa y $20 \%$ de rutilo, área específica $=50 \mathrm{~m}^{2} / \mathrm{g}$ ), utilizando una solución acuosa o alcohólica según la solubilidad de la sal de $\mathrm{Ag}, \mathrm{Fe}, \mathrm{Mo}$ o $\mathrm{Pd}$. Las sales precursoras utilizadas fueron todas reactivos analíticos: $\mathrm{AgNO}_{3}$ (Merck), $\mathrm{FeNO}_{3} .9 \mathrm{H}_{2} \mathrm{O}$ (Merck), $\left(\mathrm{NH}_{4}\right)_{6} \mathrm{Mo}_{7} \mathrm{O}_{24} .4 \mathrm{H}_{2} \mathrm{O}$ (Merck), $\mathrm{C}_{4} \mathrm{H}_{6} \mathrm{O}_{4} \mathrm{Pd}$ (Sigma). A un volumen determinado de una suspensión de $100 \mathrm{~g} / \mathrm{L}$ de $\mathrm{TiO}_{2}$ en agua desionizada se le agregó la solución de la sal precursora. La cantidad de sal empleada fue aquella que condujera a un contenido nominal de metal de 0,1 o $0,5 \%$ en peso, según el caso. Esta mezcla se mantuvo en agitación por 4 h y luego se evaporó al vacío a $60 \mathrm{rpm}$ y $80^{\circ} \mathrm{C}$. El sólido obtenido se calcinó a $500^{\circ} \mathrm{C}$ por $4 \mathrm{~h}$ en un horno mufla. Esta serie se denomina $\mathrm{M}(\mathrm{x})-\mathrm{P} 25$ ( $\mathrm{M}$ = metal $\mathrm{y} \mathrm{x}=$ contenido nominal de metal). Una muestra de $\mathrm{TiO}_{2}$, se sometió al mismo tratamiento hidrotérmico descrito, pero sin sal, para ser utilizado como referencia. Este fotocatalizador se denomina P-25R. También se preparó un fotocatalizador bimetálico por coimpregnación con soluciones de las sales de $\mathrm{Ag}$ y Mo siguiendo el procedimietno descrito anteriormente; este se denomina Ag/Mo-P25. La segunda serie de catalizadores, $\mathrm{TiO}_{2}$ y $\mathrm{TiO}_{2}$ modificado con $\mathrm{Fe}$ y/o Ag, se preparó mediante el método sol-gel descrito por Trapalis et al. (2003). Al solvente (etanol absoluto, Et-OH) se le agregó gota a gota butóxido de titanio (Ti(O-But)) con una relación molar $\mathrm{Et}-\mathrm{OH} / \mathrm{Ti}(\mathrm{O}-\mathrm{But})=55 / 1$. Posteriormente, se añadió agua desionizada en exceso con una relación molar $\mathrm{H}_{2} \mathrm{O} / \mathrm{Ti}(\mathrm{O}-\mathrm{But})=1 / 1,5$, y por último el catalizador de la hidrólisis $\left(\mathrm{HNO}_{3}\right.$ al $\left.65 \%\right)$ con una relación molar $\mathrm{HNO}_{3} / \mathrm{Ti}(\mathrm{O}-\mathrm{But})=1 / 0,173$. Esta mezcla se mantuvo en agitación constante durante $24 \mathrm{~h}$ a temperatura ambiente; seguidamente, se detuvo la agitación y se dejó a condiciones ambientales hasta su gelificación y envejecimiento por $72 \mathrm{~h}$. El gel obtenido se secó a $70^{\circ} \mathrm{C}$ en una estufa y se calcinó en un horno mufla por $2 \mathrm{~h}$ a $400^{\circ} \mathrm{C}$, el $\mathrm{TiO}_{2}$ obtenido se denomina SG. En el caso de los fotocatalizadores de $\mathrm{TiO}_{2}$ modificado con metales, a la mezcla 
inicial se le adicionó la solución de la sal precursora del metal $\left(\mathrm{AgNO}_{3} \circ \mathrm{FeNO}_{3} .9 \mathrm{H}_{2} \mathrm{O}\right)$, en una proporción tal que el contenido nominal de cada metal fue de $0,1 \%$ en peso. Esta serie de fotocatalizadores se denomina M(x)-SG.

\section{Preparación del cultivo de E. coli}

Se recuperó la cepa de Escherichia coli (ATCC 11229) en agar recuento. Se prepararon $100 \mathrm{ml}$ de medio Luria Bertani (LB; $1 \% \mathrm{p} / \mathrm{v}$ Triptona; OXOID, 0,5\% p/v Extracto de levadura; OXOID, 1\% p/v $\mathrm{NaCl}$; Carlo Erba) en agua desionizada, se separaron $10 \mathrm{~mL}$ en un tubo de ensayo estéril para la preparación de un preinóculo a partir de la cepa recuperada. El tubo con el medio inoculado se mantuvo a una temperatura de $35 \pm 2{ }^{\circ} \mathrm{C}$ y agitación constante hasta que la turbidez del sistema fue igual a 1 medido en la escala de Mc Farland; correspondiente a una concentración aproximada de $10^{7}$ unidades formadoras de colonias $/ \mathrm{mL}$ (UFC/mL). Seguidamente, el preinóculo se agregó a los 90 $\mathrm{mL}$ restantes del medio LB y se mantuvo a $35 \pm 2^{\circ} \mathrm{C}$ y agitación constante hasta que el crecimiento de la cepa alcanzó la fase estacionaria $\left(\sim 10^{9} \mathrm{UFC} / \mathrm{mL}\right)$. De este cultivo se tomó una alícuota y se centrifugó a 3000 rpm por $10 \mathrm{~min}$. El pellet de biomasa celular obtenido se lavó 2 veces más con solución salina, se resuspendió en agua desionizada y se agregó al medio de reacción.

\section{Pruebas de desinfección heliofotocatalítica}

El sistema de reacción consistió en una botella de PET previamente desinfectada, $300 \mathrm{~mL}$ de agua desionizada con una concentración celular entre $10^{7}$ y $10^{8} \mathrm{UFC} / \mathrm{mL}$ y $0,4 \mathrm{~g} / \mathrm{L}$ de fotocatalizador. Se evitó la exposición a la luz solar antes de comenzar el ensayo. Los sistemas de reacción se expusieron a la luz solar en forma horizontal sobre una superficie plana cubierta con papel de Al. Simultáneamente y de la misma manera, se colocaron dos controles: una botella sin fotocatalizador (SODIS) y otra en la oscuridad (cubierta con papel de Al). Se midió la irradiación solar de UV-A local con un radiómetro ACADUS 85-PLS (ECOSYSTEM S.A., España). Todas las pruebas se realizaron entre las 10:00 y 14:00 h correspondientes al tiempo de mayor radiación disponible en Bucaramanga (con coordenadas $7^{\circ} 08^{\prime}$ de latitud norte con respecto al meridiano de Bogotá y $73^{\circ} 08^{\prime}$ de longitud al oeste de Greenwich). Durante el proceso de desinfección, se tomaron muestras de agua cada 150 30 min que se llevaron a siembra por gota en agar recuento (Merck) y se incubaron por $24 \mathrm{~h}$ a $35 \pm$ $2^{\circ} \mathrm{C}$ para su posterior análisis. Antes de tomar cada muestra, las botellas se agitaban manualmente. Cada dato reportado corresponde al promedio de dos siembras en agar recuento. Después de la reacción, se tomó una muestra de $20 \mathrm{~mL}$ de la solución, se centrifugó por $15 \mathrm{~min}$ a $3000 \mathrm{rpm}$ y se le determinó el contenido de metal por absorción atómica (AA) para evaluar la lixiviación de metales del fotocatalizador durante la reacción. Los análisis de AA se realizaron en un espectrofotómetro BUCK Scientific modelo 210 VGP.

\section{Caracterización de los fotocatalizadores}

Se determinó la presencia de fases cristalinas en tres muestras de $\mathrm{TiO}_{2}$ (P-25, P-25R y SG) por medio de DRX en un difractómetro de polvo marca Rigaku modelo D/MAX IIIB.

\section{RESULTADOS Y DISCUSIÓN}

\section{Caracterización de los fotocatalizadores}

En la Fig. 1 se presenta el análisis por DRX de los fotocatalizadores P-25, P-25R y SG. En esta figura se observa un aumento en la intensidad de la difracción de las fases anatasa $\left(2 \theta=25^{\circ}\right)$ y rutilo $\left(2 \theta=27,5^{\circ}\right)$ en el P-25R con respecto al P-25, lo que indica que el método de preparación de los fotocatalizadores de la serie $\mathrm{M}(0,1)-\mathrm{P} 25$ induce un cambio en la cristalinidad de las fases del P-25. Hurum et al. (2003), reportan que el tratamiento térmico a $500^{\circ} \mathrm{C}$ del P-25 reduce la proporción de la fase rutilo en el material, lo que disminuye su actividad fotocatalítica. Estos autores encontraron que la relación de fases anatasa (80\%)-rutilo $(20 \%)$ en el P-25 genera un gradiente energético que separa eficientemente las cargas fotogeneradas durante la iluminación y disminuye la recombinación de las mismas. Entonces, se podría esperar una disminución de la actividad fotocatalítica en la DHFCA de los catalizadores de la serie $\mathrm{M}(0,1)-\mathrm{P} 25$ debida al cambio en la cristalinidad de las fases 
anatasa-rutilo inducido por el tratamiento térmico al que fue sometido el P-25 durante la obtención de esos fotocatalizadores. Por su parte el fotocatalizador SG presenta la fase anatasa, con un pico de intensidad a $25^{\circ}$ más ancho que el pico correspondiente para P-25 y P-25R lo que indica una menor cristalinidad en su estructura. La ausencia de la fase rutilo en el SG podría influir en la actividad fotocatalítica (Hurum et al., 2003) de los fotocatalizadores de la serie M-SG.

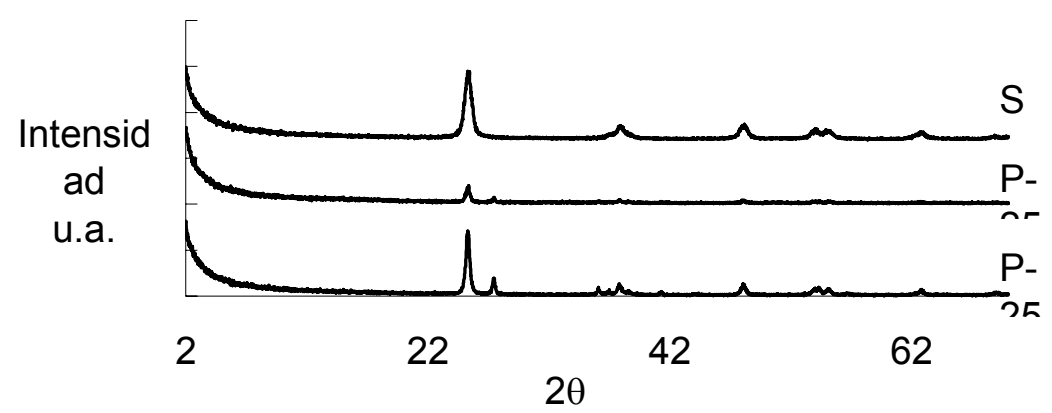

Fig. 1: Difractogramas de rayos $\mathrm{X}$ de $\mathrm{TiO}_{2}$ : SG (preparado por sol-gel), P-25 (comercial) y P-25R (comercial con proceso hidrotérmico).

\section{DHFCA con $\mathrm{TiO}_{2} \mathrm{P}-25$}

En la Fig. 2 se presenta los resultados de la DHFCA con el $\mathrm{TiO}_{2} \mathrm{P}-25$ durante $1 \mathrm{~h}$ de tratamiento y la evaluación del recrecimiento bacteriano después de un periodo de oscuridad de $24 \mathrm{~h}$. La temperatura del sistema al final de la experimentación estuvo entre 38 y $40^{\circ} \mathrm{C}$.

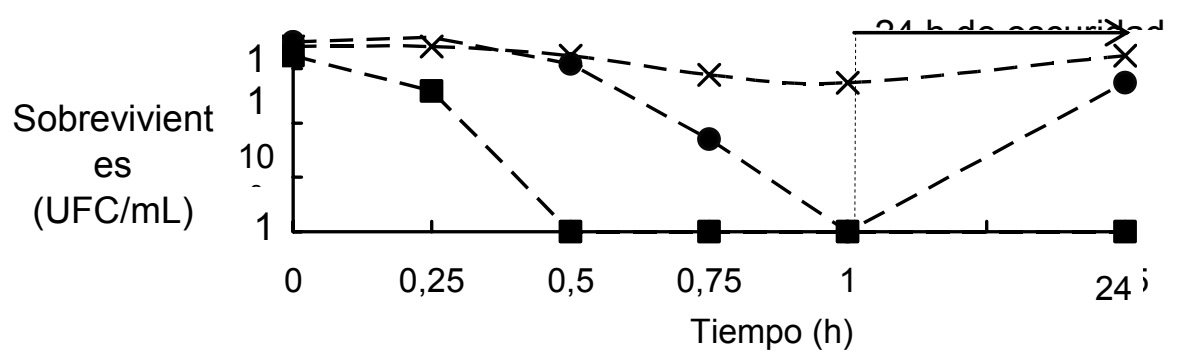

Fig. 2: DHFCA con $\mathrm{TiO}_{2} \mathrm{P}-25$ (घ), sin $\mathrm{TiO}_{2}$ o SODIS (•), sin luz (×). Irradiación UV-A acumulada durante $1 \mathrm{~h}$ de tratamiento: 27,4 Wh/m². Cepa de E. coli utilizada: ATCC 11229.

En la Fig. 2 se observa que el proceso de desinfección con $\mathrm{TiO}_{2}$ (trazo $\mathbf{m}:$ SODIS $+\mathrm{TiO}_{2}$ ) se acelera durante los primeros $15 \mathrm{~min}$ de tratamiento comparado con el tratamiento sin fotocatalizador (trazo -: SODIS). Estos resultados permiten establecer que la unión de las técnicas SODIS y fotocatalítica conduce a una disminución apreciable del tiempo de exposición al sol necesario para la eliminación de la población bacteriana de E. coli, comparado con el necesario cuando se usa la técnica SODIS sola. La efectividad del tratamiento puede observarse cuando se determina la población bacteriana después de un periodo de oscuridad de $24 \mathrm{~h}$. En el sistema SODIS, aunque se alcanza una desinfección total a $1 \mathrm{~h}$ de exposición solar, se encuentra un recrecimiento hasta $10^{5} \mathrm{UFC} / \mathrm{mL}$ después del periodo de oscuridad. Con el sistema SODIS $+\mathrm{TiO}_{2}$ se alcanza una desinfección total de un inóculo de $E$. coli con una concentración aproximada de $10^{7} \mathrm{UFC} / \mathrm{mL}$ en $300 \mathrm{~mL}$ de agua en 1 $\mathrm{h}$ de tratamiento. Este sistema no presenta recrecimiento después de $24 \mathrm{~h}$ de oscuridad. Estos resultados permiten evidenciar que el tratamiento de DHFCA presenta un efecto residual asegurando la desinfección completa de la unidosis de agua sometida al tratamiento.

DHFCA con catalizadores preparados por impregnación del TiO 2 P-25; serie $M(x)-P 25$

En la Tabla 1 se presenta los resultados de la desinfección de agua, la desinfección a $1 \mathrm{~h}$ de exposición, los valores de $\mathrm{pH}$ al inicio y al final de la experimentación, y por último el resultado de metal lixiviado al medio de reacción con cada uno de los fotocatalizadores de la serie M(0,1)-P25. En esta tabla se observa que el $\mathrm{pH}$ en todos los casos se mantuvo entre 6,0 y 7,6 , lo que indica que el 
medio de reacción es propicio para el metabolismo y reproducción de la $E$. coli. Además, se observa que se alcanza una desinfección de $99,9 \%$ con el fotocatalizador P-25. Sin embargo, la concentración final de $E$. coli fue de $3000 \mathrm{UFC} / \mathrm{mL}$ que está por encima del valor permisible para el consumo humano. Cuando se usan el Pd-P25 o el Ag-P25 se alcanza una desinfección del 100\% en ambos casos. La impregnación de $\mathrm{Pd}$ o de $\mathrm{Ag}$ sobre el $\mathrm{TiO}_{2}$ dio como resultado un fotocatalizador que potencialmente puede ser efectivo en la desinfección de agua, ya que condujo a una desactivación total de una población bacteriana alta. Al comparar el porcentaje de desinfección obtenido cuando se usan el Pd-P25 y Ag-P25 con el obtenido con el P-25R, se encuentra una diferencia de $44,4 \%$ en ambos casos, que es atribuible a la presencia de los metales Pd o Ag. Se deduce que la presencia de $\mathrm{Pd} \circ \mathrm{Ag}$ en el $\mathrm{TiO}_{2}$ fue capaz de compensar la disminución de la actividad del P-25 debida al cambio en la distribución de sus fases cristalinas ocasionado por el tratamiento térmico del procedimiento de preparación empleado. Según Linsebigler et al. (1995), la incorporación de $\mathrm{Pd}$ y otros metales nobles en el $\mathrm{TiO}_{2}$ incrementa el tiempo de vida de los electrones fotogenerados a través de una barrera de potencial en la interfase metal-semiconductor, lo que aumenta la probabilidad de que los electrones se transfieran al medio para la producción de los radicales oxidantes.

Tabla 1: DHFCA con catalizadores de la serie M(0,1)-P25 con E. coli ATCC 11229, después de 15 min de tratamiento, radiación UV-A acumulada durante el ensayo: $10,0 \mathrm{Wh} / \mathrm{m}^{2}$. $\mathrm{T}_{\text {final }}=38-40^{\circ} \mathrm{C}$. L.D.: Límite de detección.

\begin{tabular}{ccccccc}
\hline Fotocatalizador & $\begin{array}{c}{[E \text { c coli] inicial }} \\
10^{-6}(\mathrm{UFC} / \mathrm{mL})\end{array}$ & $\begin{array}{c}{[E . \mathrm{Col}] \text { final }} \\
10^{-4}(\mathrm{UFC} / \mathrm{mL})\end{array}$ & $\begin{array}{c}\text { Desactivación } \\
(\%)\end{array}$ & $\begin{array}{c}\mathrm{pH} \\
\text { inicial }\end{array}$ & $\begin{array}{c}\mathrm{pH} \\
\text { final }\end{array}$ & $\begin{array}{c}\text { Metal } \\
\text { lixiviado }\end{array}$ \\
\hline P-25 & 10,0 & 0,3 & 99,9 & 6,5 & 7,6 & -- \\
P-25R & 9,0 & 400,0 & 55,6 & 6,5 & 7,4 & -- \\
Mo-P25 & 7,5 & 700,0 & 30,0 & 6,5 & 7,0 & < L.D. \\
Pd-P25 & 11,0 & 0,0 & 100 & 6,8 & 7,1 & < L.D. \\
Fe-P25 & 8,0 & 350,0 & 56,3 & 6,5 & 7,0 & < L.D. \\
Ag-P25 & 9,0 & 0,0 & 100 & 6,0 & 7,3 & $<$ L.D. \\
SODIS & 11,0 & 700,0 & 57,0 & 6,7 & 7,0 & -- \\
\hline
\end{tabular}

De otro lado, la disminución de la actividad fotocatalítica del P-25R respecto al P-25, confirma el efecto negativo del tratamiento térmico al que se somete el $\mathrm{P}-25$, en la obtención de la serie $\mathrm{M}(0,1)$ $\mathrm{P} 25$, que como se dijo antes genera un cambio en la cristalinidad de las fases del $\mathrm{TiO}_{2}$. Los sistemas con Fe y Mo presentan niveles de desinfección relativamente bajos; 56,3 y 30,0\% respectivamente. Se esperaría que la presencia del $\mathrm{Mo}^{4+}$ y el Fe ${ }^{3+}$ aumentara la acción bactericida del P-25 ya que estos metales pueden actuar como trampas de huecos evitando la recombinación del par electrónhueco fotogenerado (Kemp y Mclntyre, 2006, Yang et al., 2002) lo que mejoraría la actividad fotocatalítica. Sin embargo, este efecto no se observa en ninguno de los dos casos, ya que la presencia de estos metales en el fotocatalizador causa una disminución en la DHFCA adicional a la causada por el tratamiento térmico. La acción bactericida de los fotocatalizadores Mo-P25 y Fe-P25 es menor que la del P-25R, e incluso menor que cuando se utiliza el sistema SODIS solo. En el caso de la impregnación con $\mathrm{Fe}$, algunos autores han encontrado que es posible la formación de $\mathrm{Fe}_{2} \mathrm{O}_{3}$, el cual se puede convertir en un centro de recombinación del par fotogenerado (Yang et al., 2002) contribuyendo a la disminución de la actividad del fotocatalizador, como la observada en este trabajo. En el caso del Mo, Kemp y Mclntyre (2006), encontraron una concentración óptima entre 0,1-0,5\% en peso de este metal en el $\mathrm{TiO}_{2}$ para la fotodegradación del poliestireno bajo lámparas de radiación UV. Es posible entonces, que la concentración del Mo usada en el presente trabajo no sea la adecuada y por lo cual deberá ajustarse si se desea alcanzar una mayor actividad con el Mo-P25 que la observada. También se podría pensar que las modificaciones realizadas al P-25 originan cambios en el punto isoeléctrico $(\mathrm{PI})$ del material y estos cambios ayudarían a explicar las diferencias observadas. Sprycha et al. (1992), evidenciaron cambios en el PI del óxido de Itrio cuando se somete a diferentes temperaturas de calcinación. Adicionalmente, Gumy et al. (2006), utilizaron varios $\mathrm{TiO}_{2}$ comerciales con diferentes propiedades fisicoquímicas y comprobaron que el PI del $\mathrm{TiO}_{2}$ afecta la eficiencia del proceso de desinfección fotocatalítica. Por lo tanto, el tratamiento térmico asociado al proceso de impregnación de los metales, además de inducir cambios en la cristalinidad de las fases del $\mathrm{TiO}_{2}$, posiblemente cambie también el PI, afectando la DHFCA. 
En la Figura 3 se muestra los resultados de la desinfección con fotocatalizadores de la serie $M(0,5)$ P25. En esta figura se observa que el sistema con el fotocatalizador con Ag (trazo $)$ ), alcanza una desinfección total en $20 \mathrm{~min}$. Sin embargo, existe un efecto mayor a la acción fotocatalítica, que es atribuible a las propiedades bacteriostáticas que por su naturaleza tiene la Ag (Gaisford et al., 2009). En el control que se hizo en oscuridad con este fotocatalizador se observó una disminución del $90 \%$ en la concentración de E. coli. Comparando el comportamiento del fotocatalizador con Mo (trazo a) con el de los otros de esta misma serie, se observa que la presencia de Mo disminuye la actividad del P-25 y retarda la acción de la Ag en el fotocatalizador coimpregnado con Ag y Mo (trazo •). Este efecto puede ser debido a que el contenido de Mo en el fotocatalizador no es el adecuado, como ha sido mostrado por Kemp y McIntyre (2006), quienes encontraron que el mejor comportamiento en la fotodesinfección se presentaba para concentraciones de Mo en un intervalo entre 0,1 y 0,5\%. Aunque la concentración utilizada en este trabajo fue de $0,5 \%$ no es la adecuada podría ajustarse para aumentar la fotoactividad del $\mathrm{TiO}_{2} \mathrm{P}-25$.

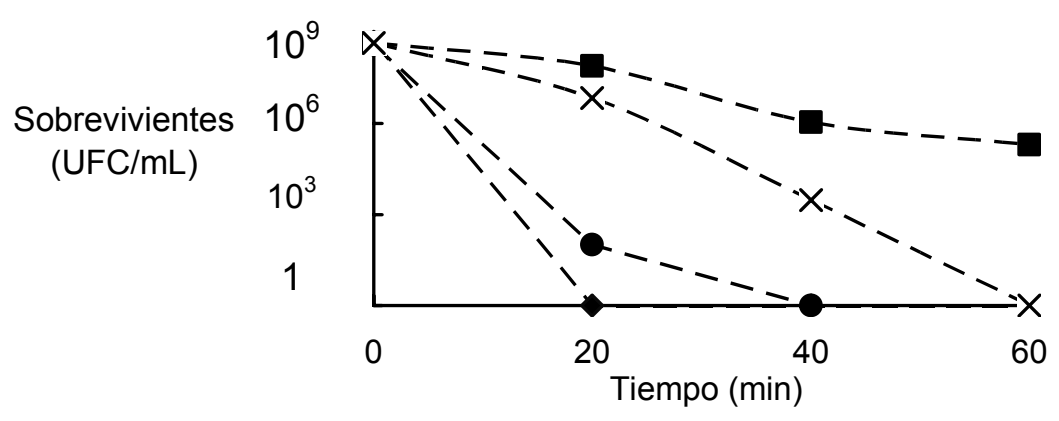

Fig. 3: DHFCA con catalizadores de la serie M(0,5)-P25, M: (•) Ag, (匹) Mo, (•) Ag/Mo, (×) P-25. Irradiación acumulada en $60 \mathrm{~min}: 77,8 \mathrm{Wh} / \mathrm{m}^{2}$. Cepa de $E$. coli utilizada: ATCC 11229.

\section{DHFCA con catalizadores preparados por el método sol-gel; serie M-SG}

En la Figura 4 se presenta los resultados de la acción bactericida de los fotocatalizadores M-SG (M $=\mathrm{Fe}$ y $\mathrm{Ag}$ ) a tres tiempos de desinfección y una radiación UV-A total acumulada de $35,2 \mathrm{Wh} / \mathrm{m}^{2}$. El $\mathrm{pH}$ de los sistemas durante el tiempo de evaluación estuvo en el intervalo de 6,9 a 8,4, que al igual que los sistemas de desinfección con los fotocatalizadores ya analizados es un medio favorable para el crecimiento de la $E$. coli. Se observa que el P-25 sigue siendo el fotocatalizador más efectivo ya que a los $30 \mathrm{~min}$ de tratamiento se encuentra una desinfección total. Por otro lado, el SG $\left(\mathrm{TiO}_{2}\right.$ obtenido por el método sol-gel) presenta una baja actividad fotocatalítica respecto al P-25. El método de preparación utilizado en este caso fue el propuesto por Trapalis et al. (2003), en el que usaron el tetraetil-ortotitanato como sal precursora de $\mathrm{TiO}_{2}$ y generaron las fases anatasa y rutilo en el fotocatalizador. Sin embargo, como se analizó anteriormente en los fotocatalizadores de la serie $\mathrm{M}(0,1) \mathrm{P}-25$, la relación de fases puede no ser la adecuada disminuyéndose la actividad fotocatalítica, como en el caso de la serie $\mathrm{M}(0,1)-\mathrm{P} 25$, ver Fig. 1.

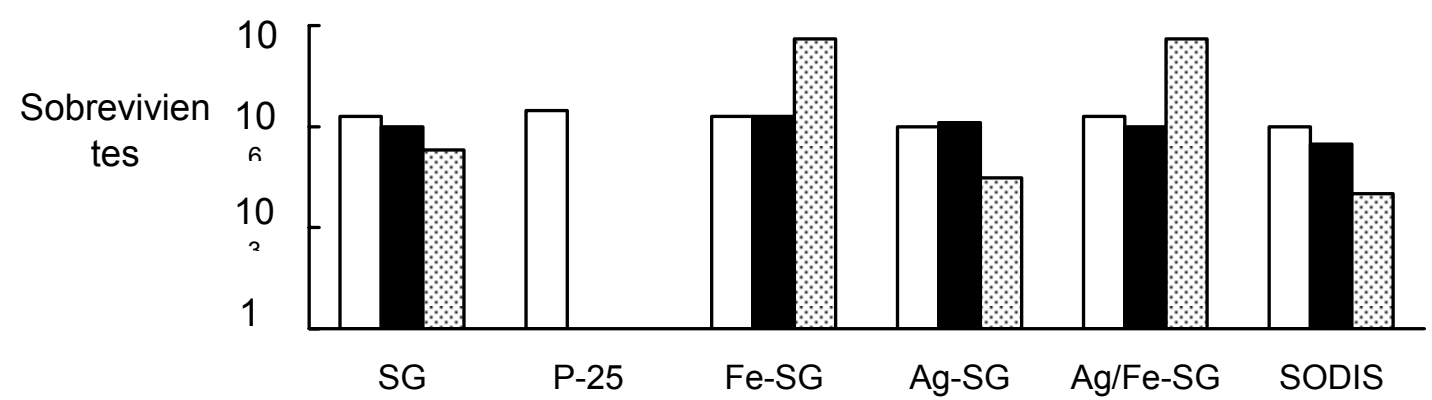

Fig. 4: Evaluación en la DHFCA de fotocatalizadores de la serie M-SG. Tiempo de tratamiento: ( $\square) 0$ min, (ロ) 30 min, y (四) 60 min. Radiación UV-A acumulada: 35,2 Wh/m². Cepa de E. coli utilizada: ATCC 11229.

Ninguno de los catalizadores de la serie M-SG presenta mayor eficiencia en la DHFCA que la presentada por el sistema SODIS. La incorporación de los metales por el método sol-gel no mejoró la eficiencia del $\mathrm{TiO}_{2}$ como se esperaba, sino por el contrario, disminuyó el efecto bactericida. En el 
caso del dopado con Ag se esperaría que el metal actuara como trampa de electrones aumentando la actividad fotocatalítica como lo reportan Xin et al. (2005). Estos autores encontraron que el ión $\mathrm{Ag}^{+}$ incorporado en la matriz de $\mathrm{TiO}_{2}$ por un método sol-gel utilizando el tert-butóxido de titanio como sal de partida, aumenta la fotoactividad. Sin embargo, en este trabajo no se produjo tal aumento. Por otro lado, el catalizador Fe-SG tampoco muestra efectividad en el proceso de desinfección; incluso, se presenta un crecimiento bacteriano durante el tiempo de tratamiento. Yang et al. (2002), encontraron un aumento en la fotoactividad del $\mathrm{TiO}_{2}$, producido por sol-gel también utilizando como sal de partida el tert-butóxido de titanio, cuando aumentaron la concentración de Fe hasta un $1 \%$ (porcentaje atómico). Es por lo tanto probable, que la no efectividad del catalizador Fe-SG puede deberse a que se usó una concentración no adecuada de $\mathrm{Fe}$ en la matriz de $\mathrm{TiO}_{2}$. Otro factor que pudo incidir en el resultado fue la sal de partida para la obtención del $\mathrm{TiO}_{2}$. En este trabajo de utilizó como sal de partida el butoxido de titanio, a diferencia de los métodos propuestos por Trapalis et al. (2003), Yang et al. (2002) y Xin et al. (2005) quienes usaron tert-butóxido de titanio y tetraetilortotitanato. Estos resultados permiten asegurar que la fotoactividad del $\mathrm{TiO}_{2}$ es muy sensible no sólo al método de preparación del fotocatalizador sino también a otras variables como la sal de titanio de partida y la concentración del metal dopante. Por lo tanto, el método de preparación del $\mathrm{TiO}_{2}$ es un factor muy importante que debe ser estudiado de forma más detallada y precisa si se desea obtener fotocatalizadores de alto desempeño en la DHFCA.

\section{CONCLUSIONES}

La unión de las técnicas solar y fotocatalítica para desinfectar unidosis de agua con una concentración de $E$. coli de aproximadamente $10^{7} \mathrm{UFC} / \mathrm{mL}$ permite disminuir el tiempo de exposición para la desinfección total a menos de 30 min a condiciones locales de Bucaramanga, Colombia y consecuentemente en zonas de alta irradiación solar. La unión de estas dos técnicas hace mucho más eficiente la DHFCA comparado con el sistema SODIS. EI $\mathrm{TiO}_{2}$ (Degussa P-25) como bactericida activado por luz solar presenta una alta actividad en la DHFCA, y ésta es aún mayor cuando se impregna con $\mathrm{Ag}$ y $\mathrm{Pd}$.

La actividad catalítica del $\mathrm{TiO}_{2}$ modificado con metales de transición depende del método de preparación del fotocatalizador (sol-gel o impregnación húmeda), de la sal de titanio de partida para el caso del sol-gel y de la concentración del metal dopante. Metales como el Mo y el Fe, a concentraciones de 0,5 y $0,1 \%$ en peso respectivamente, retardan la acción del P-25, mientras que el Pd, a una concentración de $0,1 \%$ en peso, aumenta la actividad en la DHFCA.

\section{AGRADECIMIENTOS}

Los autores agradecen a COLCIENCIAS por la financiación del proyecto código: 1102341-19419, y al grupo GIMBA-UIS por su colaboración. Camilo A. Castro agradece a Colciencias y a la UIS por la beca recibida para sus estudios doctorales.

\section{REFERENCIAS}

Carp, O., C.L. Huisman y A. Reller; Photoinduced reactivity of titaniun dioxide, Prog. Solid State Chem.: 32(1), 33-177 (2004).

Freeman, D., y C. Szymanski; PSI Sends Critical Water Purification Tools to Tsunami Survivors, (2005), http://www.psi.org/news/0105a.html, acceso: 3 de Agosto (2008).

Gaisford, S. y otros cuatro autores; An in vitro method for the quantitative determination of the antimicrobial efficacy of silver-containing wound dressings, Int. J. Pharm.: 366(1), 111-116 (2009).

Gumy, D. y otros seis autores; Catalytic activity of commercial of $\mathrm{TiO}_{2}$ powders for the abatement of the bacteria (E. coli) under solar simulated light: Influence of the isoelectric point, Appl. Catal. B : Env.: 63(1-2), 76-84 (2006).

Hermann, J.M.; Destrucción de contaminantes orgánicos por fotocatálisis heterogénea, In Solar Safe Water, $1^{\text {a }}$ edición, pp 153-170 Escuela de Posgrados UNSAM, Buenos Aires, Argentina (2005). 
Hurum, D.C., y otros cuatro autores; Explaining the enhanced photocatalytic activity of Degussa P-25 mixed phase oxide $\mathrm{TiO}_{2}$ using EPR, J. Phys. Chem.: 107(19), 4545-4549 (2003).

Kemp, T.J., y R.A. Mcintyre; Influence of transition metal-doped titanium (IV) dioxide on the photodegradation of polystyrene, Polym. Degrad. Stab.: 91(12), 3010-3019 (2006).

Linsebigler, A.L. y otros tres autores; Photocatalysis on $\mathrm{TiO}_{2}$ Surfaces: Principles, Mechanisms, and Selected Results, Chem Rev.: 95(3), 735-738 (1995).

Marin, J.M., y otros tres autores; Soporte de Nuevas Películas de $\mathrm{TiO}_{2}$ y $\mathrm{TiO}_{2} / \mathrm{SiO}_{2}$ sobre Gránulos de Poliéster para Aplicación en Fotocatálisis, Inf. Tecnol.: 19(6), 9-20 (2008).

$\mathrm{Ni}, \mathrm{M}$., y otros tres autores; A review and recent developments in photocatalytic water splitting using $\mathrm{TiO}_{2}$ for hydrogen production, Renew. Sustain. Energ. Rev.: 11(3), 401-425 (2007).

Nikolau, A., y otros tres autores; DBP Levels in Chlorinated Drinking Water: Effect of Humic Substance, Env. Monitor. Ass.: 93(1), 301-319 (2004).

Piera, E., y otros cuatro autores; Relationship concerning the nature and concentration of Fe (III) species on the surface of $\mathrm{TiO}_{2}$ particles and photocatalytic activity of the catalyst, Appl. Catal. B: Env.: 46(4), 671-685 (2003).

Rajagopal, G. y otros tres autores; Biocidal effects of photocatalytic semiconductor $\mathrm{TiO}_{2}$, Colloids and Surf. B,: 51(2), 107-111 (2006).

Rengifo-Herrera, J.A., y otros cinco autores; Escherichia coli inactivation by $N$, $S$ co-doped commercial $\mathrm{TiO}_{2}$ powders under UV and visible light, Appl. Catal. B: Env.: 84(3), 448-456 (2008).

Rincón, A.G. y C. Pulgarín; Photocatalytic inactivation of E. Coli: effect of (continous-intermittent) light intensity and of (suspended-fixed) $\mathrm{TiO}_{2}$ concentration. Appl. Catal. B: Env.: 44(3), 263-284 (2003).

Solarte, Y., y otros tres autores; Uso de la radiación solar (UV-A y temperatura) en la inactivación del Vibrio cholerae en agua para consumo humano. Factores que condicionan la eficiencia del proceso, Col. Med.: 28(3), 123-129 (1997).

Sprycha, R., J. Jablonski, y E. Matijević; Zeta potential and surface charge of monodispersed colloidal yttrium (III) oxide and basic carbonate, J. Colloid Interf. Sci.: 149(2), 561-568 (1992).

Sun, D.D., J.H. Tay, y K.M. Tan,;Photocatalytic degradation of E. coliform in water, Water Res.: 37(14), 3452-3462 (2003).

Trapalis, C.C. y otros seis autores; $\mathrm{TiO}_{2}\left(\mathrm{Fe}^{3+}\right)$ nanostructured thin films with antibacterial properties, Thin Solid Films: 433(1), 186-190 (2003).

Xin, B. y otros ocho autores; Photocatalytic activity and interfacial carrier transfer of $\mathrm{Ag}-\mathrm{TiO}_{2}$ nanoparticle films, Appl. Surf. Sci.: 252 (5), 2050-2055 (2005).

$\mathrm{Xu}$, J.C. y otros cuatro autores; Doping metal ions only onto the catalyst surface, J. Mol. Catal. A: Chem.: 219(2), 351-355 (2004).

Yang, P., y otros tres autores; Titanium dioxide nanoparticles co-doped with $\mathrm{Fe}^{3+}$ and $\mathrm{Eu}^{3+}$ ions for photocatalysis, Mat. Lett.: 57(4), 794-801 (2002).

Yuan, J. y otros tres autores; Preparations and photocatalytic hydrogen evolution of N-doped $\mathrm{TiO}_{2}$ from urea and titanium tetrachloride, Int. J. Hydrogen Energy: 31(10), 1326-1331 (2006).

Zan, L. y otros tres autores; Photocatalysis effect of nanometer $\mathrm{TiO}_{2}$ and $\mathrm{TiO}_{2}$-coated ceramic plate on Hepatitis B virus, J. Photochem. Photobiol. B.: 86(2), 165-169 (2006). 